\title{
Drug utilization, prescription errors and potential drug-drug interactions: an experience in rural Sri Lanka
}

Devarajan Rathish ${ }^{1 *}$, Sivaswamy Bahini ${ }^{1}$, Thanikai Sivakumar ${ }^{1}$, Thilani Thiranagama ${ }^{1}$, Tharmarajah Abarajithan ${ }^{2}$, Buddhika Wijerathne ${ }^{3}$, Channa Jayasumana ${ }^{1}$ and Sisira Siribaddana ${ }^{4}$

\begin{abstract}
Background: Prescription writing is a process which transfers the therapeutic message from the prescriber to the patient through the pharmacist. Prescribing errors, drug duplication and potential drug-drug interactions (pDDI) in prescriptions lead to medication error. Assessment of the above was made in prescriptions dispensed at State Pharmaceutical Corporation (SPC), Anuradhapura, Sri Lanka.

Methods: A cross sectional study was conducted. Drugs were classified according to the WHO anatomical, therapeutic chemical classification system. A three point Likert scale, a checklist and Medscape online drug interaction checker were used to assess legibility, completeness and pDDls respectively.
\end{abstract}

Results: Thousand prescriptions were collected. Majority were hand written (99.8\%) and from the private sector (73\%). The most frequently prescribed substance and subgroup were atorvastatin $(4 \%, n=3668)$ and proton pump inhibitors $(7 \%, n=3668)$ respectively. Out of the substances prescribed from the government and private sectors, 59 and $50 \%$ respectively were available in the national list of essential medicines, Sri Lanka. Patients address (5 \%), Sri Lanka Medical Council (SLMC) registration number (35\%), route (7\%), generic name (16\%), treatment symbol (48\%), diagnosis (41\%) and refill information (6\%) were seen in less than half of the prescriptions. Most were legible with effort (65\%) and illegibility was seen in $9 \%$. There was significant difference in omission and/or errors of generic name $(P=0.000)$, dose $(P=0.000)$, SLMC registration number $(P=0.000)$, and in evidence of $\mathrm{pDDI}(P=0$. 009) with regards to the sector of prescribing. The commonest subgroup involved in duplication was non-steroidal anti-inflammatory drugs (NSAIDs) (43\%; 56/130). There were 1376 potential drug interactions (466/887 prescriptions). Most common pair causing pDDI was aspirin with losartan (4 \%, $n=1376)$.

Conclusion: Atorvastatin was the most frequently prescribed substance. Fifteen percent of the prescriptions originate from government sector. SLMC registration number and trade names were seen more in prescriptions originating from the private sector. Most prescriptions were legible with effort. NSAIDs were the commonest implicated in drug class duplication. Fifty three percent of prescriptions have pDDI.

Keywords: Drug utilization, Prescription error, Prescription analysis, Drug interactions, Sri Lanka

\footnotetext{
* Correspondence: rathishdeva@gmail.com

'Department of Pharmacology, Faculty of Medicine and Allied Sciences,

Rajarata University of Sri Lanka, Saliyapura, Sri Lanka

Full list of author information is available at the end of the article
} 


\section{Background}

Prescription writing is a science, art and a basic skill that every prescriber needs to learn. It transfers the therapeutic message from the prescriber to the patient through the pharmacist [1]. An error in a prescription may introduce adverse effects and potential drug - drug interaction (pDDI). Drug related complications were found to be common in hospital based studies [2]. Guidance on prescribing is provided in the British National Formulary (BNF) and in a practical manual published by World Health Organization (WHO) [3, 4].

Knowledge on drug utilization in a particular population can be used to improve the supply of drugs to that particular population. The present drug dispensing system in Sri Lanka makes it difficult to assess drug utilization. Reasons are poor record keeping, lack of coordination between government and private sector and drug dispensing without, expired or incorrect prescriptions.

The prescribing error is defined as follows

"A clinically meaningful prescribing error occurs when, as a result of a prescribing decision or prescription writing process, there is an unintentional but significant

i. Reduction in the probability of treatment being timely and effective or

ii. Increase in the risk of harm when compared with generally accepted practice" [5].

Legibility of prescriptions is a legal duty of the prescriber. The traditional prescription writing by hand inherits high incidence of documentation errors [6]. There are instance where the prescriber has been found guilty for the death of a patient as a result of illegible prescription [7]. Previous studies have revealed the prevalence of prescribing errors in prescriptions [8].

Drug interactions lead to toxicity or therapeutic failure [9]. Resources to check pDDIs include formularies, interaction tables, prescribing \& dispensing software and drug information services (e.g.,; Stockley's Drug Interactions, Medscape, Micromedex) [9].

The Sri Lankan health system includes allopathic, ayurvedic and Sinhala medicine. Allopathic system consist a universal free government sector and the fee levying private sector. Though Sri Lanka's total expenditure on health is $3.2 \%$ of gross domestic product (GDP) for the year 2013 its health indicators are comparable with many of the more developed countries in Asia $[10,11]$.

Anuradhapura is the largest district in Northcentral province and in Sri Lanka, with a population of nearly 856,500 by 2012 [12]. Majority of its population (94.6\%) belong to the rural sector [12] and agriculture (55\%) is their main employment (unemployment rate is $3.1 \%$ ) [13]. The mean monthly household income of
Anuradhapura is Sri Lankan rupees 35,460, which is low compared to the overall mean monthly household income of the country (Sri Lankan rupees 45,878) [14]. The only tertiary care hospital available for the entire district is situated in Anuradhapura town, the teaching hospital Anuradhapura which is owned by the government. This makes it the only choice for patients of Anuradhapura to seek specialized care such as cardiology, intensive care, nephrology etc. The SPC of Sri Lanka is an institute that procures, produces and distributes pharmaceuticals with retail outlets Island wide. It was established in 1971 as a result of the work by Prof. Senaka Bibile and Dr. S.A. Wickramasinghe [15]. It promotes generic prescribing and sells drugs in a much affordable price compared to private pharmacies in the country. The only outlet of SPC in Anuradhapura is situated very closer to the teaching hospital Anuradhapura. The next outlet of SPC is either in Polonnaruwa, Kurunegala or Jaffna districts which are 100, 115 and $200 \mathrm{~km}$ away respectively [15]. Therefore large number of low income and rural population visits aforementioned SPC to obtain drugs.

In Sri Lankan health system, there are no regulations in practice to monitor drug prescription and to define the maximum number of drugs per prescription. This is a leeway for higher number of prescription errors and pDDIs per prescription.

Although there are few data from urban areas of Sri Lanka, studies on drug utilization and prescription errors of rural Sri Lanka are scarce. Knowledge on these would help identify and address issues related specifically to rural Sri Lanka. Our main objective was to assess prescriptions dispensed in rural region for drug utilization, prescription errors and pDDIs. The pDDI are due to errors in prescribing. pDDIs and prescription errors will indirectly dependent on patterns of drug utilization. Findings of the patterns of drug utilization, prescription errors and pDDIs are interrelated and cannot be segregated. This would help to address them subsequently. We chose State Pharmaceutical Corporation (SPC), Anuradhapura, Sri Lanka as our sample population.

\section{Methods}

A descriptive cross sectional study was conducted at SPC, Anuradhapura, Sri Lanka from May to August 2015. Every third prescription received at the SPC Anuradhapura was selected. The WHO anatomical, therapeutic chemical (ATC) classification system was used to group the chemical substance. At the 1st level the drugs are divided into 14 groups based on the anatomical system they act on. Second level includes therapeutic subgroups. The 3rd and 4th levels are usually pharmacological and chemical subgroups. The 5th level is the chemical substance. The classification system uses 
International non-proprietary names. If this name is not assigned to a particular drug then the system uses United States adopted name or British approved name [16]. All the chemical substances were checked for inclusiveness in the national list of essential medicines in Sri Lanka [17].

The 3 points of the likert scale used to assess legibility (the quality of being clear enough to read) were as follows: 1 - Illegible, 2 - Legible with effort and 3 - Legible. The checklist (Additional file 1) used to assess completeness included components of the prescription mentioned both in the BNF and WHO practical manual $[3,4]$. Completeness was defined for each component according to the above two resource materials. The components were:

- Patient information (name, age, gender and address)

- Prescriber information (name, signature, Sri Lanka Medical Council (SLMC) registration number below prescribers' signature, place of prescribing, contact details, qualifications and prescriber's rubber stamp)

- Drug information \{route of administration, generic name, dose, frequency, duration and information for the package label (the information written by the prescriber and copied by the pharmacist onto the label of the package. This includes the amount of drug to be taken, frequency, any specific instructions and warnings [4])\}

- Other information (date \& treatment symbol).

In addition, diagnosis of the disease and refill information was included [18-20]. Data was anonymized so identity of the patients or the prescribers was not collected. Both the assessment of legibility and filling of the checklist were done by trained Bachelor of Medicine, Bachelor of Surgery (MBBS) qualified doctors. MBBS is the first professional degree awarded, in medicine and surgery upon graduation from medical school, by universities in countries that follow the common wealth tradition. The tools were pre-tested for accuracy before the data collection proper.

Drug duplication was defined as duplication of same chemical substance in a single prescription. Drug class duplication was defined as duplication of same chemical sub-group in a single prescription.

The pDDIs were defined as each pair of drugs known for possible interactions. When a single drug combination caused pDDIs through more than one mechanism, the mechanism of the most severe pDDIs was considered. Medscape drug interaction checker was used to identify pDDIs. It is an open access information service which verifies interactions between brand and generic drugs, over-the-counter drugs and supplements [21]. Up to 30 drugs, herbals, and supplements can be checked at a time. The software is available online, as a mobile application and the results can be printed. There are three types of interactions, serious, significant and minor. The pDDIs were further categorized according to their mechanism of action; pharmacodynamics (synergism or antagonism), pharmacokinetics (absorption, distribution, metabolism or elimination), other (mechanism known but other than pharmacokinetics \& pharmacodynamics, eg alterations in serum electrolytes, alterations in sedation etc.) and unknown [21]. The data was analyzed using Microsoft Excel and SPSS version - 21. Descriptive statistics and chi square test were used to describe data. Minimum sample size was calculated as 384 prescriptions using the following formula [22]:

$$
\mathrm{SS}=\mathrm{Z}^{2} \mathrm{x}(\mathrm{P}) \mathrm{x}(1-\mathrm{P}) / \mathrm{d}^{2}
$$

SS =Sample size for infinite population (where the population is greater than 50,000 )

$\mathrm{Z}=\mathrm{Z}$ statistic for a level of confidence. For the level of confidence of $95 \%$, which is conventional, $Z$ value is 1.96 .

$\mathrm{P}=$ Expected prevalence or proportion

$\mathrm{d}=$ precision

The parameters used for calculating sample size were $95 \%$ confidence level, an expected prevalence of $50 \%$ and $5 \%$ absolute precision.

\section{Results}

Thousand prescriptions containing, 340 drugs (fifth level chemical substances) with a frequency of 3668 times from 198 classes (fourth level chemical subgroups) were collected in four calendar months. All most all were hand written $(99.8 \%)$. Most prescriptions were from the private sector (73\%; 725/1000) and $15 \%$ were from the government sector. Out of the total prescriptions $2.4 \%$ were from a hospital ward, $12.5 \%$ from an outpatient department, $27.7 \%$ from a clinic and remaining were unclassified. Mean number of drugs per prescription was 3.95 (SD 2.2). The median and mode were 4.0 and 4.0 respectively. It had a positively skewed distribution.

\section{Most frequently prescribed substances}

Atorvastatin, which is freely available in the universal free government health care system, was the most frequently prescribed drug (chemical substance) in both the government and the private and unclassified sector (Table 1). The most frequently prescribed chemical, pharmacological and therapeutic sub-groups are shown in Table 2. Twenty four different combination products were found and among them $(n=229)$ multivitamins 
Table 1 Top 10 drugs in prescriptions dispensed at SPC Anuradhapura 2015

\begin{tabular}{|c|c|c|c|c|c|}
\hline \multicolumn{2}{|l|}{ Total } & \multicolumn{2}{|l|}{ Government } & \multicolumn{2}{|c|}{ Private \& Unclassified } \\
\hline Drug & $\%(n=3668)$ & Drug & $\%(n=519)$ & Drug & $\%(n=3149)$ \\
\hline Atorvastatin & 4.0 & Atorvastatin & 7.1 & Atorvastatin & 3.5 \\
\hline Losartan & 3.8 & Losartan & 7.1 & Metformin & 3.5 \\
\hline Metformin & 3.6 & Aspirin & 6.5 & Losartan & 3.3 \\
\hline Pantoprazole & 2.9 & Metformin & 4.2 & Pantoprazole & 2.9 \\
\hline Aspirin & 2.7 & Clopidogrel & 3.3 & Gliclazide & 2.5 \\
\hline Gliclazide & 2.5 & Pantoprazole & 2.9 & Aspirin & 2.1 \\
\hline Diclofenac sodium & 1.8 & Gliclazide & 2.7 & Diclofenac sodium & 1.9 \\
\hline Celecoxib & 1.6 & Amlodipine & 2.5 & Celecoxib & 1.7 \\
\hline Clopidogrel & 1.6 & Domperidone & 2.5 & Esomeprazole & 1.6 \\
\hline Omeprazole & 1.6 & Omeprazole & 2.1 & Prednisolone & 1.6 \\
\hline
\end{tabular}

(24\%), iron with folic acid (17\%) and calcium with vitamin D (14 \%) were the most frequently prescribed (Table 3). From the chemical substances prescribed from the government sector $59 \%(306 / 519)$ are available in the national list of essential medicines, Sri Lanka and in the private sector the figure is $50 \%(1583 / 3149)$ [17].

\section{Completeness and legibility of prescriptions}

Table 4 shows assessment of completeness of the prescriptions dispensed at SPC, Anuradhapura.

Address of the patient, SLMC registration number, route of administration, generic name, treatment symbol, diagnosis and refill information were seen in less than half of the prescriptions. Information for the package label was not seen in any of the prescriptions. Out of the prescriptions which had prescriber's rubber stamp, only $39 \%$ (343/892) had the SLMC registration number. Omissions and/or errors in generic name, dose and SLMC registration number were respectively $89 \%, 72 \%, 62 \%(n=845)$ in the private sector and were significantly different when compared to $67 \%, 54 \%, 82 \%(n=155)$ in the government sector (Table 5). Most of the prescriptions were legible with effort (65\%). Legible and illegible prescriptions were 26 and $9 \%$ respectively.

\section{Drug duplication}

Drug duplication was found in three prescriptions with omeprazole, etoricoxib and cetirizine. Drug class (chemical sub-group) duplication was found in 130 out of 887 prescriptions, which had two or more drugs, involving 19 classes. The commonest was non-steroidal antiinflammatory drugs (NSAIDs) (43\%; 56/130). Chemical subgroup duplication doesn't have a significant difference with regards to the sector (Table 5).

\section{Potential drug - drug interactions}

Out of 887 prescriptions, which had two or more drugs, 466 (52.5\%) prescriptions had 1376 pDDI with a mean of 1.6 (SD 2.5) per prescription. It was a positively skewed distribution with median and mode being one and zero respectively. Out of them 94 (7\%) were serious, 1017 (74 \%) significant and 265 (19\%) minor pDDIs. Table 6 shows the commonest pDDIs categorized according to the severity. In a single prescription the maximum numbers of serious, significant and minor pDDIs were 05, 15 and 04 respectively. The highest number of pDDI in a single prescription was 21 (this prescription had 14 drugs in it). Hundred and seventy eight different drugs were involved in pDDIs. The commonest pDDI was aspirin-losartan (4\%, $n=1376)$.

Table 2 Top 5 subgroups $(n=3668)$ in prescriptions dispensed at SPC Anuradhapura 2015

\begin{tabular}{|c|c|c|c|c|c|}
\hline ATC 4th level & Percent & ATC 3rd level & Percent & ATC 2nd level & Percent \\
\hline Chemical subgroup & & Pharmacological subgroup & & Therapeutic subgroup & \\
\hline Proton pump inhibitor & 7.0 & $\begin{array}{l}\text { Anti-inflammatory and anti-rheumatic } \\
\text { products, non-steroids }\end{array}$ & 8.8 & $\begin{array}{l}\text { Anti-inflammatory and anti-rheumatic } \\
\text { products }\end{array}$ & 8.8 \\
\hline HMG CoA reductase inhibitors & 5.0 & $\begin{array}{l}\text { Blood glucose lowering drugs, excluding } \\
\text { Insulins }\end{array}$ & 8.3 & Drugs used in diabetes & 8.4 \\
\hline Angiotensin II antagonists, plain & 4.9 & $\begin{array}{l}\text { Drugs for peptic ulcer and gastro- } \\
\text { oesophageal reflux disease (GORD) }\end{array}$ & 7.6 & Drugs for acid related disorders & 7.9 \\
\hline $\begin{array}{l}\text { Platelet aggregation inhibitors } \\
\text { excluding heparin }\end{array}$ & 4.3 & Lipid modifying agents, plain & 5.8 & Anti-bacterials for systemic use & 7.3 \\
\hline Sulfonylureas & 3.6 & Angiotensin II antagonists, plain & 4.9 & Lipid modifying agents & 5.8 \\
\hline
\end{tabular}


Table 3 Combination products prescribed in prescriptions dispensed at SPC Anuradhapura 2015

\begin{tabular}{lll}
\hline No & Groups of combined preparations & $\%(n=229)$ \\
\hline 01 & Vitamins & 36 \\
02 & Anti-anemic preparations & 17 \\
03 & Mineral supplements & 14 \\
04 & Drugs for obstructive airway diseases & 11 \\
05 & Analgesics & 09 \\
06 & Corticosteroids, dermatological preparations & 04 \\
07 & Anti-acne preparations & 04 \\
08 & Drugs for acid related disorders & 02 \\
09 & Vasoprotectives & 01 \\
10 & Antifungals for dermatological use & 01 \\
11 & Anti-Parkinson drugs & 01 \\
\hline
\end{tabular}

Pharmacokinetics was the commonest mechanism involved in serious $(40.4 \%, n=94)$ and minor $(50.6 \%, n=$ 265) pDDIs. Commonest mechanism involved in significant pDDI was 'other' $(29.4 \%, n=1017)$. Additional file 2 shows commonest pDDIs for different mechanisms. pDDIs was low in the prescriptions originating from private sector $(51 \%$; 384/758) compared to the government sector (64\%; 82/129) (Table 5).

\section{Discussion}

Statins and combination of aspirin-losartan was the most frequently prescribed and commonest pDDI respectively. Patient address, SLMC registration number, route, generic name, treatment symbol, diagnosis and refill information were absent in more than half of the prescriptions. Most prescriptions were legible with effort. Almost all prescriptions were handwritten. There were no prescriptions produced by electronic prescribing system. This may be because of lack of equipment, funding, overcrowding or lack of computer literacy. Concerns on consumer security, privacy and confidentiality would have contributed [23]. Previous studies have shown that the electronic prescribing system leads to reduction of prescription errors $[18,24]$.

There were 155 prescriptions from the government sector. Unavailability of the drugs, long queues at the government drug dispensing counters and patient preference may have led to the above finding. Out of the drugs prescribed from the government and private sectors, $59 \%$ and $50 \%$ respectively were from the national list of essential medicines [17]. A study conducted in Galle, Sri Lanka during the year 2002 had found $39.6 \%$ (322/812) of the drugs prescribed in the private sector were from this national list [25]. This list of essential medicines was updated in 2014 and may have resulted in the change. The overall, rural and urban percentages of drugs prescribed from the essential drug list of a study in India were 37, 35 and 40
Table 4 Completeness of prescriptions (Total $=1000$ ) dispensed at SPC Anuradhapura 2015

\begin{tabular}{ll}
\hline Component of the prescription & $\begin{array}{l}\text { Present (complete/ } \\
\text { correct) }\end{array}$ \\
\hline Patient information & $94\left(42^{\mathrm{c}}\right)$ \\
1. Name of patient & 79 \\
2. Age of patient & 70 \\
3. Gender of patient & 5 \\
4. Address of patient & \\
Prescriber information & $90\left(98^{\mathrm{c}}\right)$ \\
5. Name of prescriber & 84 \\
6. Signature of prescriber & 35 \\
7. SLMC registration number & 76 \\
8. Place of prescribing & 53 \\
9. Contact details of prescriber & 86 \\
10. Qualifications of the prescriber & $89\left(36^{\mathrm{c}}\right)$ \\
11. Prescriber's rubber stamp containing - Full \\
name, qualifications, and registration \\
number below his signature
\end{tabular}

${ }^{a}$ Item $19 \& 20$ are in addition to the guidelines available in the BNF and WHO manual $[3,4]$

${ }^{\mathrm{b}}$ Correct, ${ }^{\mathrm{c}}$ Complete

respectively [26]. Unclassified group of prescriptions with regards to sector may be due to prescriber's negligence or non-institutional prescribing.

Average number of drugs per prescription was 3.95 with a median of four. In a previous study this number was six (median) among elderly patients in Sri Lanka [27]. In a study of 10 developing countries the average number of drugs per prescription was between 1.3 and 2.2 for general outpatient encounters [28]. This shows that number of drugs per prescription is high in Anuradhapura. Average number of drugs per prescription in rural and urban areas were 4 and 5 respectively in an Indian study [26]. Top three combination products (67 \%; 154/229) dispensed are vitamins and minerals. Lack of knowledge on rational prescribing, differences in guidelines and placebo prescribing may be the reasons. 
Table 5 Errors in prescriptions dispensed at SPC Anuradhapura 2015

\begin{tabular}{|c|c|c|c|c|c|c|c|c|c|c|c|c|c|c|c|c|}
\hline & \multicolumn{2}{|c|}{$\begin{array}{l}\text { Route } \\
(n=1000)\end{array}$} & \multicolumn{2}{|c|}{$\begin{array}{l}\text { Generic name } \\
(n=1000)\end{array}$} & \multicolumn{2}{|c|}{$\begin{array}{l}\text { Dose } \\
(n=1000)\end{array}$} & \multicolumn{2}{|c|}{$\begin{array}{l}\text { Frequency } \\
(n=1000)\end{array}$} & \multicolumn{2}{|c|}{$\begin{array}{l}\text { Duration } \\
(n=1000)\end{array}$} & \multicolumn{2}{|c|}{$\begin{array}{l}\text { pDDls } \\
(n=887)\end{array}$} & \multicolumn{2}{|c|}{$\begin{array}{l}\text { Drug class Duplication } \\
(n=887)\end{array}$} & \multicolumn{2}{|c|}{$\begin{array}{l}\text { SLMC Number } \\
(n=1000)\end{array}$} \\
\hline & $\mathrm{C}$ & I & $\mathrm{C}$ & I & $\bar{C}$ & I & C & I & C & I & $\bar{P}$ & A & $P$ & A & $C$ & I \\
\hline Government & 11 & 144 & 52 & 103 & 71 & 84 & 105 & 50 & 120 & 35 & 82 & 47 & 25 & 104 & 28 & 127 \\
\hline $\begin{array}{l}\text { Private \& } \\
\text { Unclassified }\end{array}$ & 52 & 793 & 93 & 752 & 233 & 612 & 558 & 287 & 649 & 196 & 384 & 374 & 105 & 653 & 320 & 525 \\
\hline$X^{2}(d f=1)$ & \multicolumn{2}{|c|}{0.070} & \multicolumn{2}{|l|}{51.883} & \multicolumn{2}{|l|}{19.73} & \multicolumn{2}{|l|}{0.103} & \multicolumn{2}{|c|}{0.004} & \multicolumn{2}{|c|}{6.856} & \multicolumn{2}{|l|}{2.269} & \multicolumn{2}{|l|}{21.778} \\
\hline$P$-value & \multicolumn{2}{|c|}{0.792} & \multicolumn{2}{|l|}{0.000} & \multicolumn{2}{|l|}{0.000} & \multicolumn{2}{|l|}{0.748} & \multicolumn{2}{|c|}{0.950} & \multicolumn{2}{|c|}{0.009} & \multicolumn{2}{|l|}{0.132} & \multicolumn{2}{|l|}{0.000} \\
\hline
\end{tabular}

C - Present, Correct or Complete; I - absent, Incorrect or Incomplete, P - Present; A - Absent

The US review showed antihypertensive and levothyroxine as the top chemical sub-group and chemical substance by prescriptions respectively [29]. The UK Report found amoxicillin as the top chemical substance prescribed [30]. Our study found overall proton pump inhibitors and atorvastatin as the top chemical sub-group and chemical substance by prescriptions respectively. They are also available in the government pharmacies. Antibiotics were the top chemical sub-group prescribed in a study conducted in rural India [26]. Differences in disease patterns and prescribing patterns would have contributed for the above finding.

SLMC registration number is given to all qualified doctors who practice and prescribe in Sri Lanka [31]. Using the SLMC registration number indirectly helps to stop quacks practicing medicine by identifying legitimate allopathic practioners. Only $35 \%$ of the prescriptions had the number. Even among the prescriptions $(n=890)$ that had prescriber's rubber stamp only $39 \%$ had the SLMC registration number. Absence of SLMC registration number was more common in prescriptions originating from government sector. A previous study in Kandy, Sri Lanka found SLMC registration number only in $16 \%(n=200)$ [32]. Prescribers from private sector may be more concerned about their right to prescribe and to identify themselves as western medical practitioners, hence increased use of SLMC registration number that identifies themselves as prescribers with provenance to practice allopathic medicine.

Generic name was present only in $11 \%$ of the private sector prescriptions which was lesser than in the study conducted in 2002 at the private sector of Galle, Sri Lanka (36.7\%) [25]. The drugs prescribed by generic name were 52 and $71 \%$ respectively in rural and urban India [26].

Only $48 \%$ of the prescriptions had the treatment symbol. The treatment symbol is derived from Recipe (Latin for 'take') and gives a legal validity to prescriptions. After the symbol the prescriber should write the name and strength of the drug [4].

Name, age, gender and diagnosis were missing in more prescriptions $(6 \%, 21 \%, 30 \%, 59 \%)$ of rural
Sri Lanka compared to rural India (0\%, $0 \%, 0 \%$, $28 \%)$. The prescribers signature was present in more prescriptions of rural Sri Lanka (84\%) compared to rural India (45\%).

The WHO manual and the $\operatorname{BNF}[3,4]$ has not included diagnosis and refill information however it may be important for following reasons. One drug can be prescribed for two different reasons (Eg-Propanolol in hypertension and migraine). Mentioning of diagnosis reduces confusion among the drug dispensers. Refill information (Eg - Do not repeat/Repeat once) will help curtail drug abuse and misuse. Diagnosis (41\%) and refill information $(6 \%)$ were seen in less than half of the prescriptions.

According to the WHO manual it is the legal duty of the doctor to write legibly [4]. In our study $26 \%$ of the prescriptions are legible and $9 \%$ are illegible. In Galle $26 \%(n=812)$ [25] and in Kandy $50 \%(n=200)$ [32] were illegible. However methods used to assess legibility in Kandy is not clear as it is an abstract. Legibility was 23 and $59 \%$ in rural and urban areas of India respectively [26]. However the method used to assess legibility was not clear. Compared to a study done in Saudi Arabia (1 \%) [33], drug duplication was lower in our study (0.3\%).

Consideration of pDDIs in a prescription not only helps to avoid or minimize them it also assists in monitoring and warning the patient on pDDIs. Comparison of the findings of pDDIs was made with the study done in Ahmedabad, India in 2014 [34] again using the Medscape drug interaction checker (Additional file 2). The comparison shows similarity in distribution of severity of pDDIs and commonest pharmacodynamic pDDI (aspirin-losartan). Percentage of prescriptions having pDDIs and mean pDDI per prescription was low in our study (53\% \&1.6) compared to the Indian (83\% \& 5.9). Maximum number of pDDI per prescription was 21 in our study compared to 33 in the Indian. The commonest pDDI was aspirin-losartan in our study and metoprololaspirin in the Indian [34]. The reasons for the dissimilarity may be due to the differences in the disease and prescribing pattern. 
Table 6 Common pDDls of prescriptions dispensed at SPC Anuradhapura 2015

\begin{tabular}{|c|c|}
\hline Combination (\%) & $\begin{array}{l}\text { Mechanism of pDDI according to the } \\
\text { Medscape drug interaction checker [ }\end{array}$ \\
\hline \multicolumn{2}{|l|}{ Serious (Total = 94) } \\
\hline Methotrexate-Leflunomide (6.4) & $\begin{array}{l}\text { Leflunomide increases toxicity of } \\
\text { methotrexate by pharmacodynamic } \\
\text { synergism. }\end{array}$ \\
\hline Meloxicam-Methotrexate (5.3) & $\begin{array}{l}\text { Meloxicam increases levels of } \\
\text { methotrexate by decreasing renal } \\
\text { clearance. }\end{array}$ \\
\hline Clopidogrel-Omeprazole (5.3) & $\begin{array}{l}\text { Omeprazole decreases effects of } \\
\text { clopidogrel by affecting hepatic } \\
\text { enzyme CYP2C19 metabolism. }\end{array}$ \\
\hline Clopidogrel-Esomeprazole (5.3) & $\begin{array}{l}\text { Esomeprazole decreases effects of } \\
\text { clopidogrel by affecting hepatic } \\
\text { enzyme CYP2C19 metabolism. }\end{array}$ \\
\hline Atorvastatin-Vitamin B3 (5.3) & $\begin{array}{l}\text { Either increases toxicity of the other } \\
\text { by pharmacodynamic synergism. }\end{array}$ \\
\hline Atorvastatin-Fenofibrate (5.3) & $\begin{array}{l}\text { Either increases effects of the other } \\
\text { by pharmacodynamic synergism. }\end{array}$ \\
\hline \multicolumn{2}{|l|}{ Significant (Total = 1017) } \\
\hline Aspirin-Losartan (5.5) & $\begin{array}{l}\text { Aspirin decreases effects of losartan } \\
\text { by pharmacodynamic antagonism. } \\
\text { losartan and aspirin both increase } \\
\text { serum potassium. }\end{array}$ \\
\hline Losartan-Frusemide (3.2) & $\begin{array}{l}\text { Losartan increases and furosemide } \\
\text { decreases serum potassium. }\end{array}$ \\
\hline Aspirin-Clopidogrel (3.0) & $\begin{array}{l}\text { Either increases toxicity of the other } \\
\text { by pharmacodynamic synergism. }\end{array}$ \\
\hline Clopidogrel-Pantoprazole (2.3) & $\begin{array}{l}\text { Pantoprazole decreases effects of } \\
\text { clopidogrel by affecting hepatic } \\
\text { enzyme CYP2C19 metabolism. }\end{array}$ \\
\hline Celecoxib-Diclofenac sodium (2.0) & $\begin{array}{l}\text { Celecoxib and diclofenac both increase } \\
\text { anticoagulation and serum potassium. }\end{array}$ \\
\hline Aspirin-Frusemide (2.0) & $\begin{array}{l}\text { Aspirin increases and furosemide } \\
\text { decreases serum potassium. }\end{array}$ \\
\hline
\end{tabular}

Minor $($ Total $=265)$

Glipizide - Sitagliptin (7.6)

Metformin - Vitamin B12 (5.7)

Methotrexate - Folic acid (3.4)

Aspirin-Diltiazem (2.6)

Metformin-Hydrochlorothiazide (2.6) interaction mechanism. Furosemide
Either increases effects of the other by pharmacodynamic synergism.

Metformin decreases levels of cyanocobalamin by unspecified interaction mechanism.

Metformin decreases levels of furosemide by unspecified increases levels of metformin by unspecified interaction mechanism.

Folic acid decreases effects of methotrexate by pharmacodynamic antagonism.

Diltiazem increases effects of aspirin by unknown mechanism.

Hydrochlorothiazide will increase the level or effect of metformin by basic (cationic) drug competition for renal tubular clearance. Hydrochlorothiazide decreases effects of metformin by pharmacodynamic antagonism.
Though we used the open access Medscape drug interaction checker there are formulas and commercially available drug information systems [9]. The commonest combination causing pDDIs was aspirinlosartan but a study done using the Micromedex system in a cardiac clinic at south-west Ethiopia found enalapril-frusemide as the commonest [35]. The reason may again be the differences in the epidemiology of disease and prescribing pattern. pDDIs have a significant difference with regards to the sector $(p=0.009)$. pDDIs was low in the prescriptions originating from private sector compared to the government sector. Reasons may be lack of resource to check for pDDI, lack of time to check for pDDI due to overcrowding and lack of concern.

The study had limitations such as being confined to SPC, Anuradhapura, unavailability of a standard prescription format in Sri Lanka and the pDDIs being assessed using only open access software. Yet the present study was capable in producing valuable findings which could provide a basic platform for future studies.

\section{Conclusion}

Fifteen percent of the prescriptions originate from government sector. Reasons that drive consumers away from the government drug dispensing services (where products and services are free) are not clear. SLMC registration number and trade names were seen more in prescriptions originating from the private sector. Findings on legibility, completeness, drug duplication and pDDIs show that there is room for improvement in prescriptions originating from rural Sri Lanka. Island wide studies (to find out generalized data), root cause analysis (on prescription errors) and formation of a validated prescription template (in view of regulating prescription writing) are recommended.

\section{Additional files}

Additional file 1: Assessment of legibility and completeness of prescriptions received at State Pharmaceutical Corporation, Anuradhapura-Check List. (DOC 53 kb)

Additional file 2: Comparison of findings on pDDls found by Medscape drug interaction checker. (DOC 39 kb)

\section{Abbreviations}

ATC, anatomical therapeutic and chemical; BNF, British National Formulary; GDP, gross domestic product; pDDI, potential drug-drug interaction; MBBS, Bachelor of Medicine, Bachelor of Surgery; NSAIDs, non steroidal anti inflammatory drugs; SD, standard deviation; SLMC, Sri Lanka Medical Council; SPC, State Pharmaceutical Corporation; SPSS, statistical package for the social science; UK, United Kingdom; US, United States; WHO, World Health

Organization 


\section{Funding}

The State Pharmaceutical Corporation of Sri Lanka partially funded the study It had no influence on study design, data collection, analysis, interpretation or the content of the manuscript.

\section{Availability of data and materials}

Data used in this study are given as tables and additional files. Details of materials used are available in the reference list.

\section{Authors' contributions}

DR, BW conceived the idea of the study and all authors participated in designing the study. SB, TS, T, AT were involved in data collection. All authors were involved in the analysis and interpretation of data. DR drafted the manuscript and SS, BW, CJ critically revised it. All authors read and approved the final manuscript

\section{Authors' information}

Same authors produced two oral presentations related to this study at the annual scientific sessions of Anuradhapura clinical society in October 2015 $[36,37]$.

\section{Competing interests}

The authors declare that they have no competing interests.

\section{Ethics approval and consent to participate}

Ethical clearance was obtained from the Faculty of Medicine and Allied Sciences, Rajarata University of Sri Lanka (ERC/2015/13). Institutional permission was obtained from SPC, Sri Lanka.

\section{Author details}

'Department of Pharmacology, Faculty of Medicine and Allied Sciences, Rajarata University of Sri Lanka, Saliyapura, Sri Lanka. ${ }^{2}$ Department of Physiology, Faculty of Medicine and Allied Sciences, Rajarata University of Sri Lanka, Saliyapura, Sri Lanka. ${ }^{3}$ Department of Forensic Medicine, Faculty of Medicine and Allied Sciences, Rajarata University of Sri Lanka, Saliyapura, Sri Lanka. ${ }^{4}$ Department of Medicine, Faculty of Medicine and Allied Sciences, Rajarata University of Sri Lanka, Saliyapura, Sri Lanka.

Received: 8 December 2015 Accepted: 2 June 2016

\section{Published online: 25 June 2016}

\section{References}

1. Kumari R, Idris MZ, Bhushan V, Khanna A, Agrawal M, Singh SK. Assessment of prescription pattern at the public health facilities of Lucknow district. Indian J Pharm. 2008;40:243-7.

2. Leape LL, Brennan TA, Laird N, Lawthers AG, Localio AR, Barnes BA, Hebert L, Newhouse JP, Weiler PC, Hiatt H. The nature of adverse events in hospitalized patients. Results of the Harvard Medical Practice Study II. N Engl J Med. 1991;324:377-84

3. Martin J (Ed). Prescription writing. In: British National Formulary. 58th ed. London: BMJ group, Pharmaceutical press; 2009. p. 4-5

4. De Vries TPGM, Henning RH, Hogerzeil HV, Fresle DA. Write a prescription In: Guide to Good Prescribing: A practical manual. Geneva: World Health Organization Action Programme on Essential Drugs; 1994. p. 66.

5. Dean B, Barber N, Schachter M. What is a prescribing error? Qual Health Care. 2000;9:232-7.

6. Hartel MJ, Staub LP, Röder C, Eggli S. High incidence of medication documentation errors in a Swiss university hospital due to the handwritten prescription process. BMC Health Serv Res. 2011:11:199.

7. Charatan F. Compensation awarded for death after illegible prescription West J Med. 2000;172:80

8. Bobb A, Gleason K, Husch M, Feinglass J, Yarnold PR, Noskin GA. The epidemiology of prescribing errors: the potential impact of computerized prescriber order entry. Arch Intern Med. 2004;164:785-92.

9. Snyder BD, Polasek TM, Doogue MP. Drug interactions: principles and practice. Aust Prescr. 2012:35:85-8.

10. WHO Sri Lanka World Health Organization 2015 http://www.who.int/ countries/lka/en/. Accessed 25 Nov 2015.

11. Sri Lanka's healthcare challenges The economist intelligence unit 2014 http://country.eiu.com/article.aspx?articleid $=1502512534 \&$ Country=Sri Lanka\&topic $=$ Economy\&subtopic $=$ Forecast. Accessed 25 Nov 2015.
12. Census of Population and Housing. Department of Census and Statistics, Ministry of Finance and Planning. 2012.

13. Department of Census and Statistics, Ministry of Finance and Planning Annual Bulletin, Sri Lanka Labour Force Survey. 2014.

14. Household Income and Expenditure Survey. Department of Census \& Statistics, Ministry of Policy Planning Economic Affairs, Child Youth and Cultural Affairs. 2012/2013

15. State Pharmaceuticals Corporation of Sri Lanka http://www.spc.Ik/about-spc php. Accessed 29 Oct 2015.

16. Guidelines for ATC Classification and DDD Assignment 2015. 18th edition. Oslo: WHO; 2015. http://www.whocc.no/atc_ddd_index/. Accessed 01 Oct 2015

17. National list of essential medicines, Sri Lanka 2014 [http://www.cdda.gov.lk/ index.php?option=com_content\&view=article\&id=89\&ltemid=89\&lang=en. Accesed 20 Nov 2015

18. Albarrak Al, Al Rashidi EA, Fatani RK, Al Ageel SI, Mohammed R. Assessment of legibility and completeness of handwritten and electronic prescriptions. Saudi Pharm J. 2014;22:522-7.

19. Admassie E, Begashaw B, Hailu W. Assessment of drug use practices and completeness of prescriptions in gondar university teaching referral hospital. Int J Pharm Sci Res. 2013:4:265-75.

20. Raza UA, Khursheed T, Irfan M, Abbas M, Irfan UM. Prescription patterns of general practitioners in peshawar, pakistan. Pakistan J Med Sci. 2014;30:462-5.

21. Drug Interaction Checker Medscape 2015 http://reference.medscape.com/ drug-interactionchecker. Accessed 29 Oct 2015.

22. Daniel WW. Biostatistics: A Foundation for Analysis in the Health Sciences. 7th ed. New York: John Wiley \& Sons; 1999.

23. Jayawardena DBAS: A systematic literature review of Security, Privacy and Confidentiality of patient information in Electronic Health Information Systems. Sri Lanka J Bio-Medical Informatics. 2013. doi: http://dx.doi.org/10. 4038/sljbmi.v4i2.5740.

24. Delgado Silveira E, Soler Vigil M, Pérez Menéndez-Conde C, Delgado Téllez de Cepeda L, Bermejo Viñedo T. Prescription errors after the implementation of an electronic prescribing system. Farm Hosp. 2007; 31:223-30.

25. Prasad K, Ranasinghe B. Pattern of private sector drug prescriptions in Galle: A descriptive cross sectional study. Gall Med J. 2005;10:64-8.

26. Gopalakrishnan S, Ganeshkumar P, Katta A. Assessment of prescribing practices among urban and rural general practitioners in Tamil Nadu. Indian J Pharmacol. 2013:45:252-7.

27. Liyanapathirana C, Abeyaratne DDK, Rathnamali BGA, Sumanadasa S, Mahesh PKB, Gunatilake SBL. Potentially inappropriate medication use in elderly patients (70 yrs or more) in a tertiary care hospital. In: Second Annual Academic Sessions. Colombo: Sri lanka association of Geriatric Medicine; 2015. p. 27

28. Hogerzeil HV, Bimo, Ross-Degnan D, Laing RO, Ofori-Adjei D, Santoso B, Azad Chowdhury AK, Das AM, Kafle KK, Mabadeje AF, et al. Field tests for rational drug use in twelve (12) developing countries. Lancet. 1993; 342(8884):1408-10.

29. Aitken M, Kleinrock M, Lyle J, Nass D, Caskey LA. A Review of the Use of Medicines in the U.S. in 2014. New Jersey: A report for IMS institute for health care informatics; 2015

30. Avery T, Barber N, Ghaleb B, Franklin BD, Armstrong S, Crowe S, et al. Investigating the Prevalence and Causes of Prescribing Errors in General Practice: The PRACtICe Study. Nottingham: A Report for the GMC; 2012

31. Sri Lanka Medical Council Registry 2015 [http://www.srilankamedicalcouncil. org/registry.php. Accesed 29 Oct 2015

32. de Silva KIM, Sakeena MHF, Parakramawansha KPRC. A study on accuracy and completeness of handwritten outpatient prescriptions in sri lanka. iPURSE. 2014;18:365.

33. Al-Jeraisy MI, Alanazi MQ, Abolfotouh MA. Medication prescribing errors in a pediatric inpatient tertiary care setting in Saudi Arabia. BMC Res Notes. 2011. doi:10.1186/1756-0500-4-294

34. Patel PS, Rana DA, Suthar JV, Malhotra SD, Patel VJ. A study of potential adverse drug-drug interactions among prescribed drugs in medicine outpatient department of a tertiary care teaching hospital. J basic Clin Pharm. 2014. doi:10.4103/0976-0105.134983.

35. Chelkeba L, Alemseged F, Bedada W. Assessment of potential drug-drug interactions among outpatients receiving cardiovascular medications at Jimma University specialized hospital, South West Ethiopia. Int J Basic Clin Pharmacol. 2013. doi:10.5455/2319-2003.ijbcp20130306. 
36. Rathish D, Bahini S, Sivakumar T, Thiranagama T, Abarajithan T, Wijerathne B, Jayasumana C, Siribaddana S. Assessment of legibility and completeness of prescriptions dispensed at State Pharmaceutical Corporation, Anuradhapura. Anuradhapura Med J 2015. http://dx.doi.org/10.4038/amj.v9i2Supp.7554.

37. Rathish D, Bahini S, Sivakumar T, Thiranagama T, Abarajithan T, Wijerathne B, Jayasumana C, Siribaddana S: A study on potential drug - drug interaction among prescriptions dispensed at State Pharmaceutical Corporation, Anuradhapura. Anuradhapura Med J. 2015. doi: http://dx.doi.org/10.4038/ amj.v9i2Supp.7573.

Submit your next manuscript to BioMed Central and we will help you at every step:

- We accept pre-submission inquiries

- Our selector tool helps you to find the most relevant journal

- We provide round the clock customer support

- Convenient online submission

- Thorough peer review

- Inclusion in PubMed and all major indexing services

- Maximum visibility for your research

Submit your manuscript at www.biomedcentral.com/submit 